evolutionary significance. It has been suggested by Prof. Milne, on purely theoretical grounds, that stars in general are in one of two states which may be called expanded and collapsed (Milne's centrally condensed and collapsed configurations respectively), and that the passage from one state to the other sets in at a certain critical stage in the evolutionary history and is of a cataclysmic nature. It is suggested, in short, that the evolving star, perhaps towards the end of its radiating life, becomes a nova and then a white dwarf. The outburst of radiation during the transient nova stage is the star's means of getting rid of the great difference of energy between the contiguous expanded and collapsed states. While it is still too early to be confident of the correctness of the theory underlying Milne's suggestion, the suggestion itself is a very happy one, likely-right or wrong-to prove extremely fertile. Milne's discussion already shows that an evolutionary sequence, ordinary star -nova-white dwarf, is by no means irreconcilable with the known facts, and indeed co-ordinates a great part of the facts in a most satisfying manner.

The second half of the Halley Lecture describes the present state of knowledge of the theory of stellar configurations-the generalisations that have sprung in the last three years from Eddington's pioneer work on the radiative equilibrium of a sphere of perfect highly ionised gas. These generalisations are still in an early stage of development. Milne himself, who initiated them and has been the prime mover in their development, would, I believe, be the last to claim that the equilibrium states of any model yet computed really reproduce the properties of any ordinary star. The collapsed white dwarf states appear to be simpler and to be satisfactorily accounted for by models already computed. They consist mainly of a rather cool, dense, almost isothermal core, the properties of which are controlled by those of a degenerate electron gas. But although existing models have not yet been made to mimic the observed properties of ordinary stars, we can see that this study of models has already infused new life into the theories of stellar evolution, and has taken us perhaps one long step nearer to the goal so rashly proposed as attainable in the last sentence of Eddington's " Internal Constitution of the Stars"-the goal of understanding so simple a thing as a star.

\section{R. H..F}

\title{
The British Association Standards of Electrical Resistance, I862-I932
}

\section{F} EW realise how much the electrical industry owes to the Electrical Standards Committee of the British Association, first appointed at the Manchester meeting in 1861 . We welcome, therefore, the paper entitled "Material Standard of Resistance : the B.A. Coils, 1881-1932 ", read by Sir Richard Glazebrook and Dr. Hartshorn to Section A (Mathematical and Physical Sciences), at the York meeting on September 1. The Electrical Standards Committee in its first report (Cambridge, 1862) stated that it had first to determine the most convenient unit of resistance and, secondly, the best form and material for the standard representing that unit. The C.G.S. system of measurement was the outcome of its deliberations, and this decision has done more than perhaps any other single act in simplifying and unifying electrical measurements throughout the world.

Experiments were made at King's College, London, by Maxwell and Fleeming Jenkin to obtain the ohm in a material form, and reports giving their results were issued in 1863 and 1864. In Appendix A of the Report for 1865 it was recommended that the material of the wire from which the resistance standard be made should be an alloy containing 66 per cent silver and 33 per cent platinum. It was agreed that copies of the standard should be made and preserved at Kew Observatory. In the Report for 1867 a table is given of the values of the standards in question. This Committee was dissolved in 1870. Soon after Maxwell's appointment as Cavendish professor of experimental physics at Cambridge, the coils were brought to the Cavendish Laboratory and were used by Chrystal in 1876. Lord Rayleigh succeeded Maxwell in 1879 and at once became interested in electrical measurements. Rowland of Baltimore had thrown doubts on the accuracy of the absolute measurements of the B.A. Committee. Rayleigh and Schuster's experiments at Cambridge confirmed these doubts, and from 1881 onwards great activity was shown at the Cavendish Laboratory in investigating the question of electric units. In $1879-81$, Dr. J. A. Fleming made a very careful comparison of the B.A. coils. He found that their relative values had changed appreciably, and he adopted as a definition of the B.A. unit the mean value of the resistance found from all the coils at the temperatures at which they were originally said to be correct.

The Electrical Standards Committee was reappointed in 1880; and in 1881, R. T. Glazebrook became connected with the work. He was appointed secretary in 1883 , and the coils were in his charge from that date until 1919. They are still at the National Physical Laboratory. The Standards Committee was dissolved in 1912. Up to that date, comparisons of the coils between themselves were continually in progress, and their values were determined in ohms and also in terms of the length of a column of mercury by Rayleigh, Glazebrook, Fitzpatrick, and F. E. Smith. The records show that most of the coils have changed appreciably during their long life, but that the two platinum coils included in the original group have remained unchanged.

The point of most importance that emerged from Sir Frank Smith's measurements of 1908 was the performance of the two platinum coils, now marked ' $\mathrm{D}$ ' and ' $\mathrm{E}$ '. The value of these coils in B.A. units in 1888,1908 , and 1932 obtained from a comparison

No. 3286, Vor. 130] 
with mercury tubes, assuming that the resistance of 1 metre of mercury is 0.95352 B.A. units, is given in the accompanying table:

\begin{tabular}{|c|c|c|c|}
\hline Coil. & 1888 (R. T. G.) & 1908 (F. E. S.). & 1832 (Hartshorn). \\
\hline D & 1.00013 & 1.00012 & 1.00011 \\
E & 1.00073 & 1.00072 & 1.00071 \\
\hline
\end{tabular}

The coils have been very carefully intercompared this year at the National Physical Laboratory and their value determined in terms of the international ohm by Dr. Hartshorn. The international ohm is defined as the resistance at $0^{\circ} \mathrm{C}$. of a column of mercury $106.300 \mathrm{~cm}$. in length and $1 \mathrm{sq} . \mathrm{mm}$. in cross section. Tables are given illustrating how the values found for the coils during the last sixty-five years have varied. These show that considerable variations appeared prior to 1888 . These depend probably on errors arising in the temperature determinations of ' $D$ ' and ' $E$ ', as an uncertainty in the temperature of these coils of $0 \cdot 1^{\circ} \mathrm{C}$. implies an uncertainty of 0.0003 B.A. units in the resistance measurements.

In the platinum-silver coils ' $F$ ' and ' $G$ ' appreci- able changes were noted between 1880 and 1908 . These are probably due to the fact that during that period the coils were on several occasions measured at $0^{\circ} \mathrm{C}$.; strains may have been produced at the soft soldered joints. In recent years, when the coils have been maintained at a temperature not far removed from $16^{\circ} \mathrm{C}$, the changes have been remarkably small.

The main conclusion to be drawn from the series of investigations from 1865 to the present date is that the platinum coils ' $D$ ' and ' $E$ ' have retained their value unchanged, while changes have occurred in all the coils made of alloys. These changes are partly due to the violent temperature changes to which all the coils have been subjected at various times.

We may also conclude that pure metals like platinum are usually more stable in their properties than alloys like manganin. Unfortunately, the pure metals suitable for standards have tempera. ture coefficients varying from 0.003 to 0.007 , so measurements would have to be taken at $0^{\circ} \mathrm{C}$., as this is practically the only temperature at which they can be maintained sufficiently constant.

\section{Obituary}

\section{Prof. W. Stirling}

$\mathrm{W}^{1}$ ILLIAM STIRLING, formerly Brackenbury professor of physiology at the University of Manchester, died on October 1. Prior to his going to Manchester he held the regius chair of the Institutes of Medicine at Aberdeen.

Stirling was born at Grangemouth in 1851, received his early education at the Dollar Academy and then became an undergraduate at Edinburgh. Here he had a career of great distinction, graduating as B.Sc. in 1870 and two years later as D.Sc., M.B. and C.M. In his medical final examination he was awarded first class honours. He also gained the Baxter scholarship, the Falconer fellowship and Ettles prize. His thesis in 1875 on "The Summation of Electrical Stimuli applied to the Skin" brought him the M.D. degree and with it the gold medal. After his student career in Edinburgh he worked in Leipzig, Berlin and Paris; and then returned to Edinburgh as demonstrator under Rutherford. His election to the regius chair at Aberdeen shortly after this time and when he was but twenty-six years old, indicates clearly the great promise of his early years and the esteem in which he was held.

After eleven years in Aberdeen, during which time he introduced there the practical teaching of physiology, Stirling was elected as successor to Arthur Gamgee in the chair of physiology at Owens College, Manchester. Here he remained until his retirement in 1919.

Stirling became a professional physiologist at a time when the teaching of physiology in many of the medical schools of Great Britain was inadequate and very little research work was done. In France and Germany, however, the subject in the hands of such masters as Bernard, Helmholz and Ludwig, had developed into an important experimental science. It is not surprising, therefore, that Stirling's sojourn abroad inspired in him a great affection for the men under whom he had studied, and this was apparent from his frequent references to them in his lectures and in private conversation. Carl Ludwig especially was held by him in great regard.

Nevertheless, although in his early post-graduate days Stirling carried out promising research work, he eventually became an interpreter of the work of others rather than an investigator himself. Both at Aberdeen and in Manchester, he introduced elaborate methods of teaching and was largely responsible in the latter school for the extension of the medical building which houses the present physiological laboratories. In addition to his work for his own department at Manchester, Stirling acted as Dean of the Medical School from 1902 until 1913, showing himself to be a capable administrator and devoting himself wholeheartedly to the general welfare of the School. It is probable that these heavy administrative duties coupled with the labours involved in bringing into being the new medical buildings were largely responsible for the attention he devoted to exposition rather than to physiological research. Of his publications, probably the best known are his "Apostles of Physiology", "Outlines of Practical Physiology" and the "Text Book of Physiology" by Landois and Stirling; the last-named being a translation of Landois's book, to which Stirling made many valuable additions.

Stirling was a man who made many friends and did not easily lose them. His fine stature, impres-

No. 3286, Vol. 130] 